\title{
A Smart Home environment to support risk monitoring for the elderly living independently
}

\author{
Tongai Chiridza ${ }^{a}$, Janet Wesson ${ }^{a}$, Dieter Vogts ${ }^{a}$ \\ ${ }^{a}$ Computing Sciences Department, Nelson Mandela University, South Africa
}

\section{ABSTRACT}

Elderly people prefer to live independently despite being vulnerable to age-related challenges. Constant monitoring is required in cases where the elderly are living alone. The home environment can be a dangerous environment for the elderly due to adverse events that can occur at any time. The potential risks for the elderly living independently can be categorised as injury in the home, home environmental risks, and inactivity due to unconsciousness.

The aim of this paper is to discuss the development of a low-cost Smart Home Environment (SHE) that can support risk and safety monitoring for the elderly living independently. An unobtrusive and low cost SHE prototype that uses a Raspberry Pi 3 model B, a Microsoft Kinect Sensor and an Aeotec 4-in-1 Multisensor was designed and implemented. An experimental evaluation was conducted to determine the accuracy with which the prototype SHE detected abnormal events. The results show that the prototype has a mean accuracy, sensitivity and specificity of $94 \%, 96.92 \%$ and $88.93 \%$ respectively. The sensitivity shows that the chance of the prototype missing a risk situation is $3.08 \%$, and the specificity shows that the chance of incorrectly classifying a non-risk situation is $11.07 \%$.
\end{abstract}

Keywords: ambient assisted living, ambient intelligence, context-awareness, elderly, remote monitoring, smart home environment

Categories: • Human-centered computing $\sim$ Ubiquitous and mobile computing design and evaluation methods

\section{Email:}

Tongai Chiridza s210153679@mandela.ac.za (CORRESPONDING),

Janet Wesson j.wesson@mandela.ac.za,

Dieter Vogts d.vogts@mandela.ac.za
Article history:

Received: 28 Aug 2017

Accepted: 1 Apr 2019

Available online: 24 Jul 2019

\section{INTRODUCTION}

The elderly prefer to live independently in their homes, in many cases without anyone to watch over them. If an elderly person is living alone, it is important that he/she is monitored constantly as emergency situations can arise at any time. Independence and safety are critical issues for older adults as they face age-related challenges, or risks such as falls, forgetfulness, sensory impairment, immobility and isolation (Demiris, Hensel, Skubic, \& Rantz, 2008).

Chiridza, T. Wesson, J. and Vogts, D. (2019). A Smart Home environment to support risk monitoring for the elderly

living independently. South African Computer Journal 31(1), 1-23. https://doi.org/10.18489/sacj.v31i1.534

Copyright (C) the author(s); published under a Creative Commons NonCommercial 4.0 License (CC BY-NC 4.0).

$S A C J$ is a publication of the South African Institute of Computer Scientists and Information Technologists. ISSN 1015-7999 (print) ISSN 2313-7835 (online). 
There are limited options for people who are responsible for taking care of the elderly. The number of elderly people requiring healthcare and continuous monitoring is increasing every year, and, at the same time, the number of people of working age is decreasing (Röcker, 2013). The typical people who are involved in the care of the elderly are caregivers, family members and clinicians (Chiridza, Wesson, \& Vogts, 2016). Caregivers and family members harbour diverging values and attitudes towards their joint efforts in providing healthcare for the elderly. A risk factor that can be attached to these diverging values is the abuse of the elderly person involved (Christensen \& Grönvall, 2011).

Family members are emotionally attached to the care they provide to their ageing relatives. Caregivers can be emotionally detached to the care and assistance they provide to the respective elderly person. It is therefore necessary to understand the attitudes and values of the relevant actors and incorporate them in the design of the technologies that can assist in providing the necessary safety and risk monitoring.

Nursing homes provide an option for ageing adults who need constant surveillance, but may not be a perfect solution (Liu \& Zuo, 2012). This leads to a situation in which there are more elderly people needing care than people who can actually provide care. The elderly often resist the option of moving into a nursing home or assisted living facility (Mckinley, 2014).

Bodily functional decline can be exhibited through falling, memory loss and collapsing. Morris et al. (vergaard Hansen, 2014) identified that falls and injuries are common in the elderly. The inability to move leads to the inability to call emergency services, family or caregivers. The probability of being unassisted when an emergency occurs increases as loneliness sets in for the elderly (Costa, Castillo, Novais, Fernández-Caballero, \& Simoes, 2012).

Smart Home Environments (SHEs) have been proposed as an emerging space for positive ageing, due to their potential to increase the ease and safety in performing domestic tasks and improving communication (Lê, Nguyen, \& Barnett, 2012). SHEs can facilitate independent living for the elderly by providing them with emergency assistance, fall prevention or detection, reminder systems, medication administration and assistance for those with hearing, visual or cognitive impairments (Cheek, Nikpour, \& Nowlin, 2005).

\subsection{Problem statement}

The elderly population is increasing in South Africa (Gómez-Olivé, Thorogood, Clark, Kahn, \& Tollman, 2013). Longevity is associated with bodily functional decline, which can manifest itself as sensory impairment, chronic ailments and cognitive impairment. The elderly prefer to live independently despite the risks associated with longevity. These issues present new challenges in supporting safety and risk monitoring for the elderly. Living independently and being alone can result in no one being able to intervene if emergency situations occur.

Existing solutions have proved inadequate due to issues surrounding their adoption. Lack of privacy, high cost, perceived ease of use and extensibility impact on the adoption of existing technologies that support safety and risk monitoring in the home. Many elderly people live on a fixed income and are not able to afford expensive equipment, and are not keen to learn new technologies. 
Society has not developed solid and cost effective solutions for the well-being, safety, healthcare and social needs of the elderly to support active ageing (Deen, 2015).

\subsection{Methodology}

The main objective was to design and develop a SHE that can support safety and risk monitoring for the elderly living independently. The Design Science Research (DSR) methodology (Prat, ComynWattiau, \& Akoka, 2014) was used in the design and development of the SHE prototype. DSR involves the creation of artefacts that solve real-life problems. An artefact in DSR can be described as a construct, model, methods or instantiations. The artefact is designed, implemented and evaluated using well-executed evaluation methods. In this case, the artefact is the SHE prototype. DSR provides clear and verifiable contributions to the design of a SHE for this research. Typical components of DSR include a Relevance Cycle, a Design Cycle and Rigor Cycle.

The Relevance Cycle includes understanding the problem, exploring existing knowledge and tools, choosing methods and planning processes. The research is grounded in a philosophical research perspective (Hevner \& Florida, 2011). The Relevance Cycle consists of literature and existing systems review. Opportunities for better solutions can be derived from the synthesis of the existing literature and systems. User requirements are identified in the Relevance Cycle. Requirements can be obtained by using questionnaires, or focus group interviews.

The Design Cycle includes the design of a prototype that can satisfy the requirements obtained in the Relevance Cycle. The prototype is iteratively built and evaluated in this cycle. Processes are also evaluated and updated in the Design Cycle. The Design Cycle will discuss how the SHE prototype was developed. Continuous evaluation will be used to justify the various components of the design. Field studies, surveys and simulation can also form part of the evaluation.

The Rigor Cycle shares similar functions to the Design Cycle. It consists of continuous evaluation and updates to the design of the SHE. The Rigor Cycle is an iterative process throughout the life of a project and strives to align the design to established frameworks.

DSR was the research methodology of choice for this research because it enabled us to analyse the advantages and shortcomings of existing systems and/or models for SHEs that support safety and risk monitoring for the elderly. Another advantage derived from using DSR was that it ensures that a proper understanding of the problem is established. DSR also emphasises the evaluation of the final product (Prat et al., 2014), and this helps in determining if the SHE can support safety and risk monitoring for the elderly living independently.

The research objectives were as follows:

1. To identify the risks facing the elderly living independently and how they can be monitored in the home.

2. To review the existing solutions and/or technologies and tools that can be used to support affordable safety and risk monitoring for the elderly living independently.

3. To design a SHE prototype using low cost devices. 
4. To evaluate the accuracy and consistency of the SHE prototype in supporting safety and risk monitoring.

\section{RISKS FACING THE ELDERLY}

The Relevance Cycle involved exploring the problems and opportunities for the elderly living alone. The main deliverables for the Relevance Cycle were the functional and non-functional requirements.

The home environment can be a dangerous environment for the elderly living independently. The risks identified from previous research include: injury in the home, home environment risks and adverse medical events that can occur at any time (Chiridza et al., 2016). Falling is a common risk factor for injury in the home.

Figure 1 illustrates the common causes of falling. The category of concern is uncontrollable falls, which result from chronic medical conditions, neurological function, age, gender and the history of falls. Chronic cardiovascular conditions, such as hypertension, can result in the elderly collapsing or fainting at any moment. Elderly females are more prone to falling than their male counterparts (Chiarini, Ray, Akter, Masella, \& Ganz, 2013). The medication that an elderly person is taking also has an impact on the risk of falling. The risk of falling due to medication increases significantly if a person is on more than four medications simultaneously (Todd \& Skelton, 2004).

Home environment variables, such as ambient temperature, can be too high or too low and can have a negative impact on the resident. Exposing the elderly to extreme temperatures can contribute to injury or worsening of their health condition; for elderly persons, extreme temperature is any temperature less than $15^{\circ} \mathrm{C}$ or greater than $32^{\circ} \mathrm{C}$ (Wold, 2012).

The ability of the body to maintain body temperature is affected by humidity, ambient temperature and air movement. Hypothermia and hyperthermia can easily result in death in the elderly. High humidity and high temperature affect the normal cooling mechanisms of the body in the elderly, and this can result in heat exhaustion and heatstroke. Hyperthermia has deadly effects in persons with cardiovascular problems, because of the strain it imposes on the heart and blood vessels during attempts to cool down (Wold, 2012).

Adverse medical emergencies are also common for the elderly with chronic ailments. An emergency could require admission to a medical facility or it could require certain drugs to be administered immediately ("Home Accident Prevention for Elderly", 2002). Elderly persons suffering from chronic ailments and cognitive impairment need constant monitoring so that when an emergency occurs, they can be quickly attended to. Cardiovascular Diseases (CVD) are the leading causes of death in the elderly (Villalba et al., 2007). Heart failure is an example of a Cardiovascular Disease and mainly affects people older than 65 years.

The elderly can forget their emergency numbers and where they placed their phones. Serious complications or death can result from a lack of emergency medical assistance. It is important to understand the risks facing the elderly before implementing a suitable design. Interacting with the elderly can help in eliciting their safety and risk monitoring requirements. A focus group interview with the elderly was conducted to elicit their requirements. 


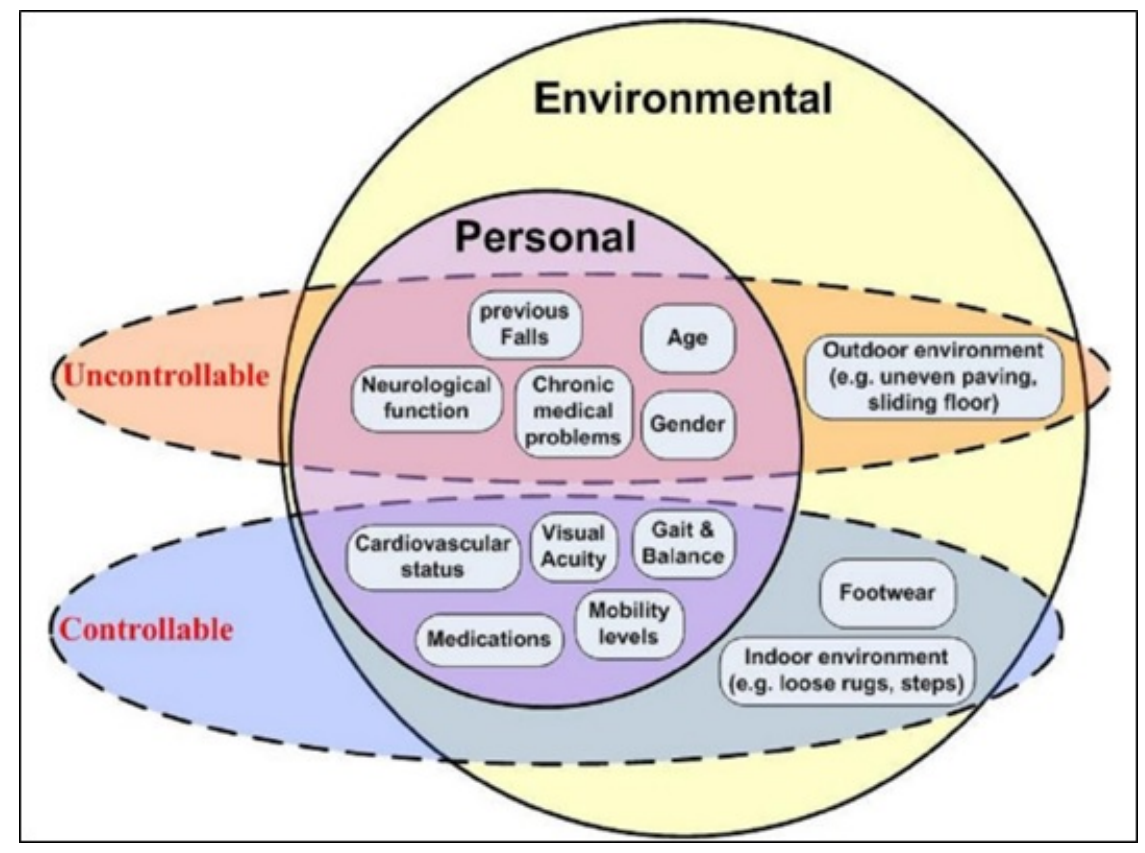

Figure 1: Falling categories and common causes (El-Bendary, Tan, Pivot, \& Lam, 2013)

\section{FOCUS GROUP INTERVIEW}

A focus group interview comprises a group of people assembled by a principal investigator to discuss and comment on a topic from a personal perspective (Burrows, Gooberman-Hill, \& Coyle, 2015). Focus group interviews enable researchers to examine not only what people think, but also how they think and why they think that way, through tapping into the different forms of communication that people use daily (Doody, Slevin, \& Taggart, 2013). The number of participants can vary between 4-6 and there should be a good balance in the group's diversity (Breen, 2006). A focus group interview is also part of the relevance cycle under the DSR methodology.

A focus group interview was conducted with the elderly staying in a retirement village in Summerstrand, Port Elizabeth in accordance with ethics approval from the Ethics committee at Nelson Mandela University. A total of seven participants attended the interview session; six females and 1 male. The average age was 70 years and they all lived alone. Focus group interviews with the elderly are difficult to setup as they are not all available at the same time. Some old age homes were not welcome to participating in the study. The focus group interview was conducted by a moderator. The principal researcher is not always the best person to act as a moderator, as he/she may not have necessary skills and may presuppose the solution required (Powell \& Single, 1996). Before the commencement of the focus group interview, the moderator gave an overview of the topic.

The elderly participants were given an opportunity to sign consent and confidentiality forms. The interview questions were then distributed. The questions began with general issues progressing to more specific problems. The focus group moderator used a probing technique. The probing 
technique is used to obtain answers from participants and to encourage discussion (Breen, 2006). The role of the principal investigator was to transcribe notes and answer technical questions from the participants.

Initially, it was not known what to expect, therefore the question was designed to be as general as possible. The question that was asked was; "what kinds of risks would you find useful to have monitored in your home-either for your own "heads-up" warning and/or for centralised/family monitoring and warning?"

The discussions from the meeting were summarised into the Word map shown in Figure 2. Although the elderly have panic buttons, they all agreed that they do not use them consistently. Some said they always keep them on their bedside in case something happens at night, but they do not carry them during the day. Panic buttons are not water resistant hence they cannot be worn during bathing, laundry or doing dishes. Four out of seven participants said that they do not bother to use their panic buttons, because they feel that they are not going to get help from the resident nurse anyway. They would rather call a friend or a relative for help.

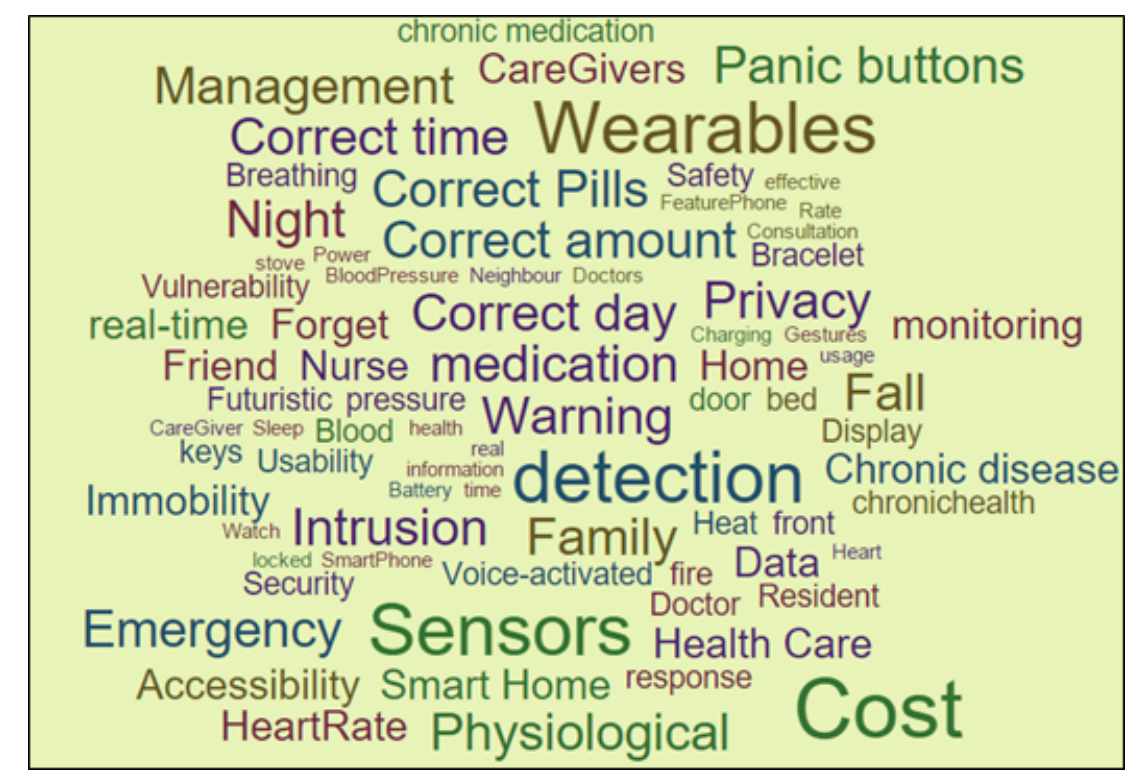

Figure 2: Word map for the focus group interview discussion outcomes

Participants were worried about the possibility of a fire breaking out in the event that they forget to turn off their stoves or there is an electrical fault. They stressed that the sensors should not be intrusive and they would prefer to use natural interaction, for example voice. The use of wearables to measure physiological measures was identified as being acceptable by the participants.

The elderly expressed concern about the cost of the technology that would meet their requirements. Concerns were also raised regarding battery powered technology. They were worried about the battery life and forgetting to charge their devices. The usability and user experience of the technology was also noted as a cause of concern. None of the participants had a smart phone. They said feature 
phones are easier to use than smart phones. The participants said that they do not use the phones often and they would prefer to have information displayed on a bigger screen, such as a television set.

The following section discusses the requirements obtained from literature review and the focus group interview.

\section{REQUIREMENTS}

There are three core features of the domain of home automation: emergency assistance, autonomy enhancement and comfort (see Figure 3). Emergency assistance is concerned with the detection and prediction of emergency situations. The assistance and preventive measures that can be implemented depend on the nature of the emergency situation detected or predicted. The focus group interview reinforced the literature requirements of the need for low cost and unobtrusive risk monitoring systems in the home of the elderly. Autonomy enhancement includes higher level goals like medication, dressing, eating, cooking and cleaning.

Comfort is the overarching goal in home care design and incorporates emergency assistance and autonomy enhancement. Safety falls under the comfort category. Guaranteed emergency intervention ensures comfort and peace of mind to all actors involved. This paper focuses on emergency assistance, particularly the detection, prediction and sending out of alerts.

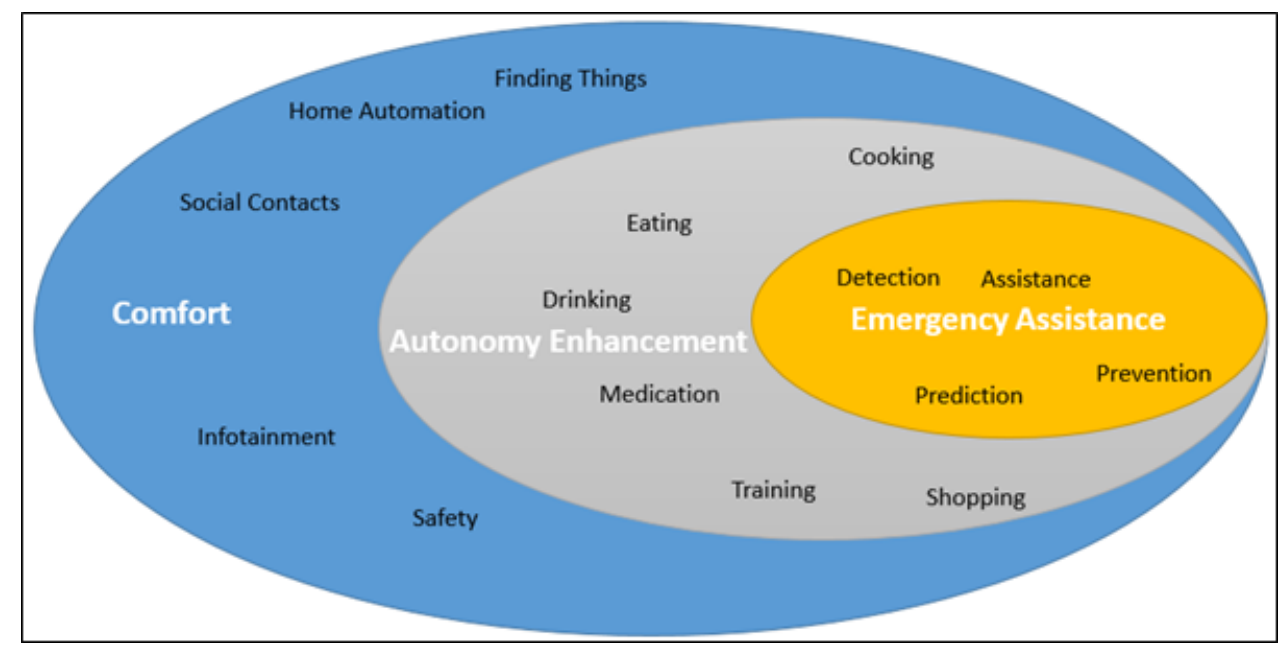

Figure 3: Common categories for home automation (Thomas, Becker, Ras, Holzinger, \& Müller, 2007)

The requirements identified for the purposes of this research were summarised as fall detection, home environment monitoring, inactivity monitoring and emergency notification. The three actors considered were the elderly resident, a caregiver and a family member.

Activity monitoring in this context encompasses fall detection, inactivity detection and motion sensors. If a fall occurs, the system should automatically send an SMS to the relatives or caregivers. 
If there is inactivity in the home for a certain duration, an alarm should be sent to relatives or a caregiver. Relatives and caregivers should be able to view the activity log of the elderly person at any point in time.

\section{EXISTING SOLUTIONS}

There are a variety of solutions and theoretical models that have been been proposed to try and address the safety and risk monitoring requirements of the elderly. Some of the models and technologies identified for the purposes of this paper are summarised in the following sections.

\subsection{Home monitoring}

Sensors have been developed to measure home environmental variables such as temperature, lighting, humidity, motion, pressure and sound. The data collected from these sensors can be analysed to determine if risks such as a rapid increase in temperature or low humidity have occurred. The cost of home monitoring sensors is decreasing and they are becoming smaller in size. Most of the existing systems, however, do not combine the data collected from the sensors and do not perfom an accurate prediction of emergency situations. The existing solutions exist as "data silos" with limited integration with other solutions.

\subsection{Adverse medical events}

Mobile technologies have some compelling benefits in disease prevention, chronic disease management and improving healthcare (Chiarini et al., 2013). There are many applications for mobile healthcare management for the elderly. Mobile health or mHealth broadly refers to health-related services offered to patients by caregivers and clinicians through mobile technology platforms on cellular or wireless networks (Chiarini et al., 2013). mHealth applications generate a lot of data, which is not centralised, but rather exists as distinct data silos due to the variety of vendors available on the market.

Devices designed for mHealth tend to be obtrusive; they have to be worn and have to be within the communication range of each other. The learnability of interacting with these systems is a key issue that impacts on the adoption of mHealth application. Furthermore, mHealth applications exist as distinct stand alone systems, making it difficult to integrate the data collected with other systems. The cost of buying these vendor agnonstic solutions is relatively high for the elderly on a fixed income.

\subsection{Activity monitoring and fall detection}

There are different kinds of falls ranging from falls from walking or standing, falls from sleeping on the bed and falls from sitting in a chair (Mubashir, Shao, \& Seed, 2013). Various techniques have been proposed for fall detection and reporting on the detected fall. Mubashir et al. (2013) reviewed 
some of the existing fall detection techniques and categorised the techniques into three sub-sections, as illustrated in Figure 4.

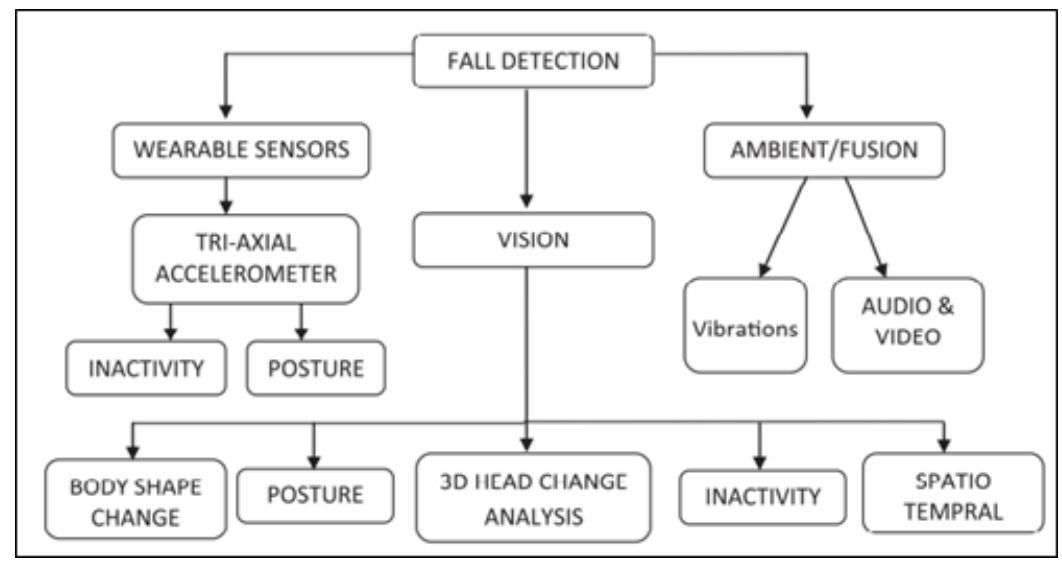

Figure 4: Classification of fall detection strategies (Mubashir, Shao, \& Seed, 2013)

Table 1 below summarises the advantages and disadvantages of the sttategies illustrated in Figure 4.

The main drawbacks of the existing systems is their obtrusive nature in data collection, learnability, cost and status as distinct stand alone systems. Elderly users do not want direct interaction with the technologies; they prefer to be unaware that they are being monitored. Wearable devices still need to be worn and the elderly can easily forget to wear them, hence they will be of limited use.

\section{DESIGN AND IMPLEMENTATION}

The architecture of the proposed SHE consists of four layers as illustrated in Figure 5.

The first layer is the sensing layer which consists of the Aeotec 4-in-1 multisensor and the Microsoft Xbox 360 Kinect. The Aeotec 4-in-1 sensor measures the temperature, humidity, lighting and motion. The Kinect provides color and depth information as video streams. At the time of this research the cost of the equipment was as follows:

- Raspberry Pi 3-R650.00

- Aeotec 4-in-1 Multisensor-R899.00

- Z-Wave Controller-R199.00

- Microsoft Xbox Kinect-R2000.00

The communication layer consists of the Z-Wave, Wi-Fi and Bluetooth communication protocols to transmit the data to the data processing and computation layer. The key component of the data 
Table 1: Advantages and disadvantages of identified fall detection strategies

\begin{tabular}{|c|c|c|c|}
\hline Strategy & Sensor type/s & Advantages & Disadvantages \\
\hline Non-vision & $\begin{array}{l}\text { Wearable device, } \\
\text { smartphones }\end{array}$ & $\begin{array}{l}\text { Wearable devices are relatively } \\
\text { cheap, and their adoption is on the } \\
\text { increase. Smart phones have in } \\
\text { built sensors, which can be } \\
\text { leveraged to determine posture, } \\
\text { and used to deduce whether there } \\
\text { was a fall. }\end{array}$ & $\begin{array}{l}\text { Users must wear the device all the } \\
\text { time. Focus group participants } \\
\text { raised concern about } \\
\text { misplacing/forgetting the phone } \\
\text { and the battery life. Some of them } \\
\text { still use feature phones and have } \\
\text { limited knowledge of how to use } \\
\text { smartphones. }\end{array}$ \\
\hline $\begin{array}{l}\text { Ambient } \\
\text { fusion }\end{array}$ & Acoustic sensor & Unobtrusive detection of falls & $\begin{array}{l}\text { Acoustic sensors are not accurate. } \\
\text { Sound and vibrations cannot } \\
\text { distinguish between a deliberate } \\
\text { event and an actual event }\end{array}$ \\
\hline $\begin{array}{l}\text { Computer } \\
\text { vision }\end{array}$ & $\begin{array}{l}\text { Cameras, depth } \\
\text { cameras, infra-red } \\
\text { cameras }\end{array}$ & $\begin{array}{l}\text { Off the shelf cameras are now } \\
\text { cheaper. Posture change and } \\
\text { inactivity can be determined with } \\
\text { better accuracy as compared to } \\
\text { acoustic sensors and wearables. } \\
\text { Depth cameraas can be used where } \\
\text { privacy is a concern. Infrared } \\
\text { cameras allow tracking in the dark. }\end{array}$ & $\begin{array}{l}\text { Privacy is an issue whenever } \\
\text { cameras are to be used. The elderly } \\
\text { raised the issue of privacy; they } \\
\text { would not want someone to see } \\
\text { them undress or doing anything } \\
\text { regarded as private }\end{array}$ \\
\hline
\end{tabular}

processing and computation layer is the Raspberry Pi 3. An open source Smart Home Operating System, called openHAB (OpenHAB, 2016), was installed on the Raspberry Pi in order to collect data from the multisensor. OpenHAB utilises the Z-Wave protocol to collect data from the Aeotec sensor.

Any sensor or item is considered a thing in OpenHAB and this makes it easily extensible to support multiple sensors. OpenHAB provides a rule engine, which can be used to process rules and scripts that are executed when certain conditions are met. OpenHAB also offers cloud computing, which allows for real-time remote monitoring. Push notifications can be sent when certain thresholds are reached by the home environment variables. The data is stored in a mySQL database server on the Raspberry Pi and a copy of the data is saved in the myOpenHAB cloud server.

The data processing and computation layer consisted of the activity monitoring module, fall detection module and the rule set for determining risks from the sensor data. OpenCV and Python were used to process the video stream coming from the Kinect in order to determine fall detection. Depth data was obtained from the Kinect using the Libfreenect library. OpenCV was used to perfom feature extraction, using the BackgroundSubtractorMOG2 algorithm (Zivkovic \& Van Der Heijden, 2006).

The fall detection algorithm allows for statistical background image and per pixel Bayesian segmentation, which is much better than comparing the time spent in a specific region. Fall detection was determined by comparing the area covered by the posture to precalculated posture areas at various distances from the Kinect. The three postures of concern were identified as standing, sitting and lying down. Any posture in between was extrapolated.

The services and applications layer consists of a mobile app that shows the home environment 


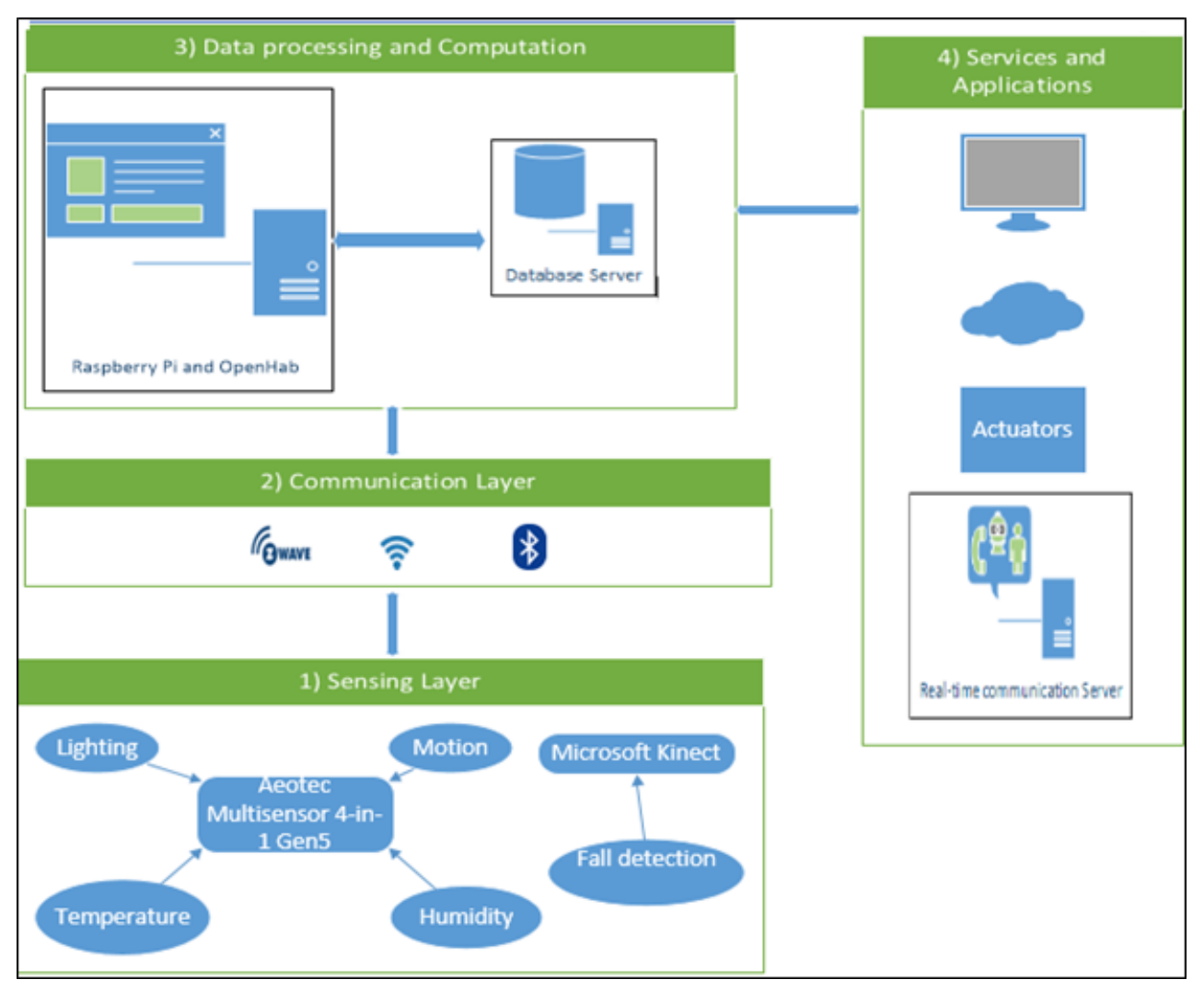

Figure 5: System architecture for the SHE prototype

variables. The mobile app allows for relatives or caregivers in remote locations to have a realtime view of the home environment variables and for receiving push notifications. Figure 6 illustrates the mobile app developed for home environment monitoring.

Variations in the values during the day are shown in form of graphs on the app. Figure 7 shows an example graph showing the variation in motion during the day. 


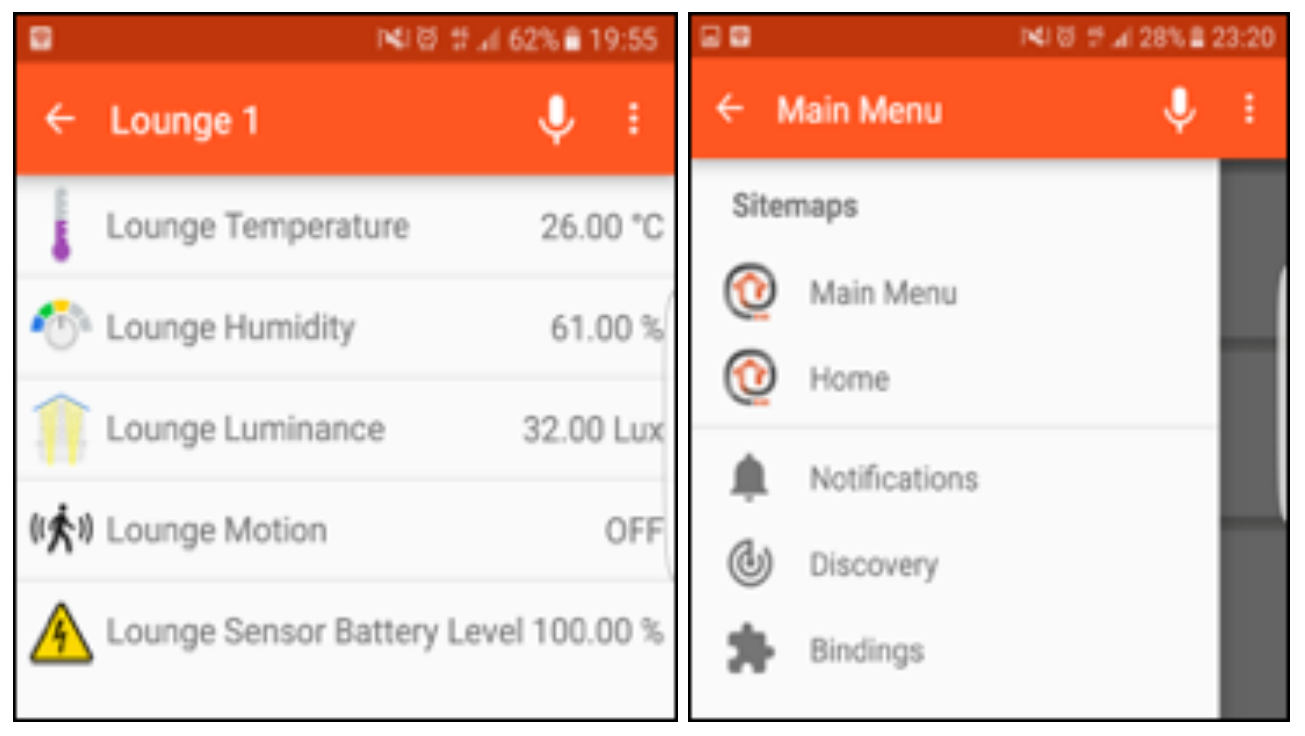

Figure 6: Dashboard showing sensor variables

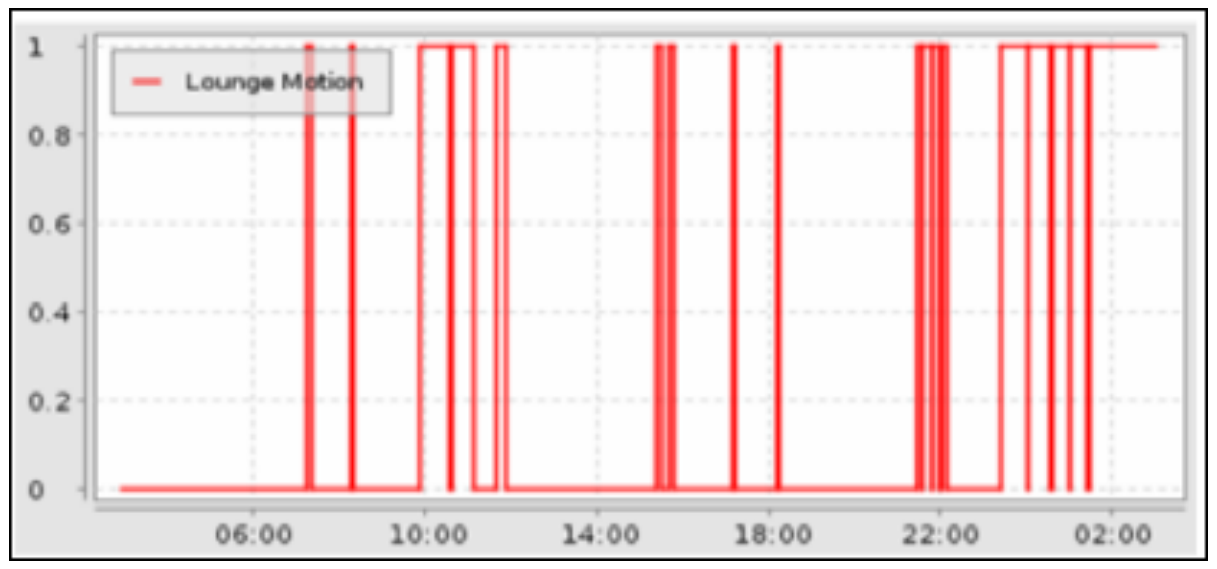

Figure 7: Motion vs. time graph in a SHE 
Risk determination and the sending of the corresponding notifications were achieved by developing a set of rules. All rules share a common execution context, and therefore they can exchange values with each other. The rule triggers can be Item based triggers, time based or system based triggers. Item based triggers react to events on the openHAB event bus and the time based triggers react at special times. The system based triggers react depending on certain system statuses.

Periods of inactivity in the home can be identified easily from the graph because no motion will be recorded. Longer periods of inactivity can be a sign of a potential risk occurrence. If the elderly person wakes up at 6am everyday and on a particular day there is no motion from 6am to 7am then that might mean there is something wrong. A notifcation can be sent to the relative or caregiver informing them of the potential risk. If the temperature is higher or lower than set limits a notifcation is sent.

The notifications sent are as shown below in Figure 8. Notifications are better than panic buttons because they are triggered without the input of the user. Depending on the severity of the notification the receiver will be able to take appropriate actions. In order to determine the accuracy

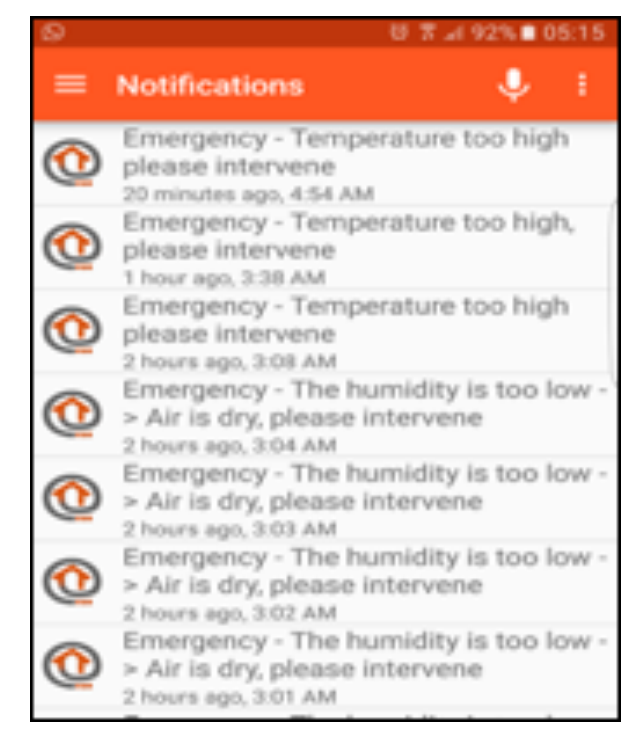

Figure 8: Example notifications sent to caregiver or relative

and consistency of the SHE prototype, an experimental evaluation was perfomed as discussed in the following section.

\section{EVALUATION}

The overall goal of the evaluation was to determine the accuracy, sensitivity, specificity and consistency of the SHE prototype. The evaluation constitutes the Rigor cycle within the DSR methodology. The artefact is evalauted against a specific set of metrics to determine if the objectives have been met. 
The metrics considered for the evaluation of the prototype are discussed in Section 7.1. The feedback and issues identified during evalaution can be incorporated into future research and modifications of the developed prototype.

The selected method for evaluation was an ex post evaluation consisting of a laboratory experiment. An ex post evaluation is one in which a system, model or technology is evaluated after it is acquired or implemented (Pries-Heje, Baskerville, \& Venable, 2008). The experimental evaluation consisted of a simulation of risk situations that can be experienced in the home. The results obtained from the laboratory experiment can be used to determine the accuracy, sensitivity, specificity and consistency of the system (Hjalmarsson \& Rudmark, 2012). The experiment was conducted in the Centre of Excellence (CoE) laboratory at Nelson Mandela University and the researcher and the research supervisors acted as participants. The main variables considered in the evaluation were lighting, temperature, humidity, motion, posture and time.

The expectation was that the SHE prototype should correctly identify all the risk situations from a sequence of events presented. Each risk situation could have one of the following outcomes: true positive, true negative, false positive or false negative. A true positive (TP) is when the system accurately detects an expected positive outcome. A false positive (FP) is when an event is falsely classified as having occurred when it did not occur (Belshaw, Taati, Jasper, \& Mihailidis, 2012). A true negative (TN) is when the system accurately detects that there was no risk situation, while a false negative (FN) is an incorrect negative prediction (Belshaw et al., 2012).

SHE prototypes can be evaluated in a realistic environmental setting with a participant performing actual tasks (Koshmak, Loutfi, \& Lindén, 2015). Each scenario comprises tasks that can be carefully modelled to depict an envisioned real life situation, i.e. risk situation (Moeller et al., 2004). Each scenario comprised at least the following: time duration, default condition, test condition and expected results. A total of 20 scenarios were developed to measure each of the metrics mentioned in the goal of the evaluation. Each scenario had a time duration, a default condition, a test condition and the expected result. For each scenario, scripts were given to the participants to follow.

Rashidi and Cook (Rashidi, Cook, Holder, \& Schmitter-Edgecombe, 2011) recruited a participant to evaluate their SHE implementation of activity tracking. They compressed the day's events into one hour performing different tasks for a specified duration. The same approach was used in this evaluation, where each evaluation comprising all the identified scenarios was compressed into 1.5 hours. Table 2 and Table 3 illustrate the scenarios that were developed for the evaluation.

Each scenario was simulated using a script. A script is a sequence of instructions that must be followed in performing a simulation of a risk situation (Cook \& Krishnan, 2014). The abnormal events considered included high and low temperatures, high and low humidity, lighting being on or off, motion detection and fall detection. A combination of these events was also used for evaluation. Table 4 shows the scripts that were used during evaluation.

The time duration for each script was made absolute for evaluation purposes so as to simulate the scenarios as they would unfold during the course of the day. Four scenarios were described for fall detection: falling from standing, falling from a seated position, falling when walking, and simply lying down on the floor from standing. The results were recorded as one of the four options: true positive, true negative, false positive and false negative. 
Table 2: Evaluation scenarios which should result in a true positive

\begin{tabular}{|c|c|c|c|c|c|c|c|c|c|}
\hline \multirow[t]{2}{*}{ ID } & \multirow[t]{2}{*}{ Duration } & \multirow[t]{2}{*}{ Description } & \multirow[t]{2}{*}{ Default condition } & \multirow[b]{2}{*}{ temperature } & \multicolumn{4}{|c|}{ Test condition } & \multirow[t]{2}{*}{ Outcome } \\
\hline & & & & & motion & lighting & humidity & posture & \\
\hline SC1 & - & High temperature & $0 \leq d T \leq 5$ & $d T<5$ & - & - & - & - & Emergency notification \\
\hline SC2 & - & Low temperature & $0 \leq d T \leq 5$ & $d T<-5$ & - & - & - & - & Emergency notification \\
\hline SC3 & - & High humidity & $0<d H<20$ & - & - & - & $d H \geq 20$ & - & Warning notification \\
\hline SC4 & - & Low humidity & $0<d H<20$ & - & - & - & $d H \leq-20$ & - & Warning notification \\
\hline SC5 & 5 & Inactivity & $\begin{array}{l}\text { Random movement in the } \\
\text { home }\end{array}$ & - & OFF & - & - & Lying down & Information notification \\
\hline SC6 & 5 & $\begin{array}{l}\text { Inactivity and } \\
\text { possible } \\
\text { unconsciousness }\end{array}$ & $\begin{array}{l}\text { Random movement in the } \\
\text { home }\end{array}$ & $d T \geq 5$ & OFF & $d L u x=0$ & $d H \geq 20$ & Lying down & Emergency notification \\
\hline SC7 & 5 & $\begin{array}{l}\text { Sleeping past } \\
\text { normal wake up } \\
\text { time }\end{array}$ & $\begin{array}{l}\text { Change in lighting and } \\
\text { motion is detected }\end{array}$ & - & OFF & $L u x=0$ & - & Lying down & Warning notification \\
\hline SC8 & 5 & $\begin{array}{l}\text { Insomnia / } \\
\text { restlessness }\end{array}$ & Resident should be asleep & - & ON & $d \operatorname{Lux}>0$ & - & $\begin{array}{l}\text { Seated / standing } \\
\text { / walking }\end{array}$ & Warning notification \\
\hline SC9 & 5 & $\begin{array}{l}\text { Emergency at } \\
\text { night }\end{array}$ & $\begin{array}{l}\text { Temperature should not } \\
\text { increase while the resident } \\
\text { is asleep }\end{array}$ & $d T \geq 5$ & OFF & $\operatorname{Lux}>0$ & - & Lying down & Emergency notification \\
\hline SC10 & 2 & Intruder presence & $\begin{array}{l}\text { Motion should not be } \\
\text { registered in the dark and } \\
\text { occupant lying down }\end{array}$ & - & ON & $\operatorname{Lux}=0$ & - & Lying down & Emergency notification \\
\hline SC11 & $d t<1$ & $\begin{array}{l}\text { Fall from standing } \\
\text { position }\end{array}$ & $\begin{array}{l}\text { Slow transition from } \\
\text { standing to lying down } \\
d t>1.0 \mathrm{~s}\end{array}$ & - & - & - & - & $\begin{array}{l}\text { Standing - lying } \\
\text { down } d t<1.0 s\end{array}$ & Emergency notification \\
\hline SC12 & $d t<1$ & Fall from seating & $\begin{array}{l}\text { Slow transition from sitting } \\
\text { to lying down } d t>1.0 \mathrm{~s}\end{array}$ & - & - & - & - & $\begin{array}{l}\text { Seated - lying } \\
\text { down } d t<1.0 s\end{array}$ & Emergency notification \\
\hline SC13 & $d t<1$ & $\begin{array}{l}\text { Walk a few steps } \\
\text { and fall }\end{array}$ & $\begin{array}{l}\text { Slow transition from } \\
\text { standing to lying down } \\
d t>1.0 \mathrm{~s}\end{array}$ & - & ON & - & - & $\begin{array}{l}\text { Standing - lying } \\
\text { down } d t<1.0 s\end{array}$ & Emergency notification \\
\hline
\end{tabular}


Table 3: Test scenarios for expected true negative outcome

\begin{tabular}{|c|c|c|c|c|c|c|c|c|c|}
\hline \multirow[t]{2}{*}{ ID } & \multirow[t]{2}{*}{ Duration } & \multirow[t]{2}{*}{ Description } & \multirow[t]{2}{*}{ Default condition } & \multicolumn{5}{|c|}{ Test condition } & \multirow[t]{2}{*}{ Outcome } \\
\hline & & & & temperature & motion & lighting & humidity & posture & \\
\hline SC14 & - & $\begin{array}{l}\text { Normal room } \\
\text { temperature }\end{array}$ & $0<d T<5$ & $0<d T<5$ & - & - & - & - & Normal \\
\hline SC15 & - & Waking up & $\begin{array}{l}\text { Change in lighting and } \\
\text { motion is detected }\end{array}$ & & ON & $\operatorname{Lux}>0$ & - & Standing & Information \\
\hline SC16 & - & Normal humidity & $0<d H<20$ & - & - & - & $0<d H<20$ & - & Normal \\
\hline SC17 & - & Frequent activity & $\begin{array}{l}\text { Random movement in the } \\
\text { home }\end{array}$ & - & ON & $\operatorname{Lux}>0$ & - & - & Normal \\
\hline SC18 & - & Sleeping & Resident should be asleep & - & OFF & $\operatorname{Lux}=0$ & - & Lying down & Normal \\
\hline SC19 & $d t>1$ & Lying down & $\begin{array}{l}\text { Slow transition from } \\
\text { standing to lying down }\end{array}$ & - & - & - & - & Standing - lying down & Normal \\
\hline SC20 & - & Sitting down & $\begin{array}{l}\text { Slow transition from } \\
\text { standing to sitting down }\end{array}$ & - & - & - & - & Standing - sitting & Normal \\
\hline
\end{tabular}


Table 4: Scripts for simulating the evaluation scenarios

\begin{tabular}{|c|c|c|c|c|}
\hline ID & Description & Goal & Duration (mins) & Procedure \\
\hline T01 & $\begin{array}{l}\text { Temperature } \\
\text { increase }\end{array}$ & $\begin{array}{l}\text { To increase the temperature in the home } \\
\text { by at least } 5 \text { degrees Celsius }\end{array}$ & - & $\begin{array}{l}\text { 1. Turn on the heater } \\
\text { 2. Leave it on until the temperature has increased by at least } 5^{\circ} \mathrm{C}\end{array}$ \\
\hline T02 & Low temperature & $\begin{array}{l}\text { To decrease the temperature in the home } \\
\text { by at least } 5 \text { degrees Celsius }\end{array}$ & - & $\begin{array}{l}\text { 1. Turn on the air conditioner } \\
\text { 2. Decrease the temperature by at least } 5^{\circ} \mathrm{C}\end{array}$ \\
\hline T03 & High humidity & Increase the humidity by at least $20 \%$ & - & $\begin{array}{l}\text { 1. Position a kettle underneath the sensor } \\
\text { 2. Turn on the kettle } \\
\text { 3. Leave the kettle to boil }\end{array}$ \\
\hline T04 & Low humidity & Decrease the humidity by at least $20 \%$ & - & 1. This script should follow directly after the high humidity \\
\hline T05 & $\begin{array}{l}\text { Inactivity in the } \\
\text { home }\end{array}$ & $\begin{array}{l}\text { To detect absence of motion and lying } \\
\text { down for a long period }\end{array}$ & 5 & 1. Lie down for five minutes \\
\hline T06 & Sleeping & $\begin{array}{l}\text { To detect there has not been activity at the } \\
\text { expected time of waking up }\end{array}$ & 5 & $\begin{array}{l}\text { 1. Turn off the lights } \\
\text { 2. Do not move/leave the room for } 30 \text { minutes }\end{array}$ \\
\hline T07 & $\begin{array}{l}\text { Inactivity in the } \\
\text { home and high } \\
\text { temperature }\end{array}$ & To detect inactivity and high temperature & 5 & $\begin{array}{l}\text { 1. Turn on the heater } \\
\text { 2. Lie on the mattress, do not move or leave the room }\end{array}$ \\
\hline T08 & $\begin{array}{l}\text { Falling from } \\
\text { standing }\end{array}$ & To detect a fall from a standing position & 5 & $\begin{array}{l}\text { 1. Put the mattress in the area under the Kinect } \\
\text { 2. Perform a fall onto the mattress } \\
\text { 3. Keep lying down for } 5 \text { minutes }\end{array}$ \\
\hline T09 & Falling from seated & To detect a fall from a seated position & 5 & $\begin{array}{l}\text { 1. Put a chair at the end of the mattress } \\
\text { 2. Fall from the chair onto the mattress } \\
\text { 3. Keep lying down for more than } 5 \text { minutes without moving }\end{array}$ \\
\hline $\mathrm{T} 10$ & Fall when walking & To detect a fall when walking & $1 \mathrm{~s}$ & $\begin{array}{l}\text { 1. Make sure the mattress is in the path } \\
\text { 2. Walk a few steps and fall onto the mattress }\end{array}$ \\
\hline T11 & $\begin{array}{l}\text { Emergency at } \\
\text { night }\end{array}$ & To detect unusual activity at night & 5 & $\begin{array}{l}\text { 1. Turn on the lights } \\
\text { 2. Move around, sitting down in between movements } \\
\text { 3. Turn on heater or air conditioner }\end{array}$ \\
\hline T12 & $\begin{array}{l}\text { Additional } \\
\text { presence }\end{array}$ & To detect the presence of an intruder & 2 & $\begin{array}{l}\text { 1. Turn off the lights } \\
\text { 2. Sleeping } \\
\text { 3. Detect movement in the room }\end{array}$ \\
\hline
\end{tabular}


A total of five participants were selected for the evaluation. Each scenario was performed a total of five times by each participant. Repeating a script more than five times is redundant as results tend to become more uniform after five repetitions (Doody et al., 2013). The equipment used during the evaluation included the Aeotec 4-in-1 multisensor, Kinect, Raspberry Pi, Heater and a mattress.

Elderly participants could not be used for evaluation purposes because of the risk of real physical injury. In future, the prototype will need to be installed for a period of time in the homes of the elderly to determine its actual effectiveness, acceptance and accuracy in the real world. The following section discusses the evaluation metrics for this research.

\subsection{Accuracy}

Accuracy can be defined as the degree to which the result of a measurement, calculation or specification conforms to the correct value or standard (Prat et al., 2014). The accuracy (Acc) can be calculated as the number of all correct predictions (TPs) divided by the total number of events, i.e., positive $(\mathrm{P})$ and negative $(\mathrm{N})$ events, as shown in Equation 1:

$$
A c c=\frac{T P+T N}{P+N}
$$

An accuracy of 1.0 is the best result that can be obtained, and an accuracy of 0.0 is the worst (Saito \& Rehmsmeier, 2017). The error rate (Err) can also be used to deduce the accuracy of the system and can be calculated as shown in Equation 2:

$$
\operatorname{Err}=1-A c c
$$

The error rate should ideally be equal to zero, but in some systems a small value close to zero is acceptable.

\subsection{Sensitivity and specificity}

There is a direct relationship between accuracy, sensitivity (SN) and specificity (SP). Sensitivity can be defined as the degree to which a system can quickly detect or respond to slight changes (Delahoz \& Labrador, 2014). The sensitivity of system in detecting risk situations measures the probability of detection. Equation 3 shows how to calculate SN.

$$
S N=\frac{T P}{T P+F N}
$$

The best sensitivity is 1.0, which shows that no TPs were missed, and the worst is 0.0 .

The specificity can be defined as the quality of belonging to a particular standard (Delahoz \& Labrador, 2014). It is also known as the true negative rate, because it measures the number of TNs that have not been missed. Specificity is calculated using Equation 4:

$$
S P=\frac{T N}{T N+F P}
$$

A SP result of 1.0 is the best result, whereas the worst result is a specificity of 0.0 . 


\subsection{Consistency}

The consistency of the SHE can be derived from the variation of the results by repeating the events several times. A large variation in the measures calculated for each event's test set shows that the system is not consistent in detecting risk events. The ideal result is that the scores obtained from calculating the measures such as accuracy, should not vary for each event test set. The results obtained from the evaluation are discussed in Section 7.4 below.

\subsection{Results}

The test scenarios were each repeated five times. Test 1 had an accuracy of $85 \%$, mainly due to Scenario 9 and Scenario 12. Scenario 9 involved increasing the temperature while the participant was lying down. The scenario led to a FN when the anticipated result was TP. This discrepancy can be attributed to the fact that the system had warned of the high temperature and failed to proceed to the rule that checks the participant's posture.

Scenario 12 involved falling from a sitting position and the outcome was classified as FN. This discrepancy could be because of the time taken for the fall or the participant did not remain still after the fall. Test 2, Test 3 and Test 5 had constant values of $95 \%$, because they had the same number of TPs and TNs. Test 4 had a result of $100 \%$, which means that no false notifications were sent, i.e. there were no FPs and FNs.

In Test 2 and Test 5 the accuracy was reduced by the outcome of Scenario 19, which was expected to yield a TN instead of a FP. Scenario 19 comprised a slow transition from a standing to a lying position. The outcome of the scenario was detected as a fall instead of someone lying down on the floor from a standing position. This outcome can be attributed to the fact that the time duration for the event was faster than the predefined value and also the participant was not lying still for the specified duration.

The results are summarised in Figure 9. An average accuracy of 94\% was obtained from the results of the evaluation with an error rate of $6 \%$. The average sensitivity obtained was $96.92 \%$ and the average specificity was $88.93 \%$. These results show that the rate of not missing a TP was $96.92 \%$ and the rate of not missing a TN was $88.93 \%$. In comparison to the evaluation results from similar work, the SHE prototype was able to accurately and consistently support safety and risk monitoring in accordance with the requirements of the elderly living independently. Fall detection systems and risk monitoring systems notification systems are not $100 \%$ accurate, due to various limitations, which result in false positives (El-Bendary, Tan, Pivot, \& Lam, 2013)

In an experimental evaluation of an acoustic-based fall detection system consisting of 120 falls and non-falls, a $97.50 \%$ fall detection rate was recorded with a 3\% false detection (Lim, Park, Kim, Kim, \& Yu, 2014). A computer vision based algorithm was evaluated and had a correct detection rate of $84.44 \%$ (El-Bendary et al., 2013). In another similar fall detection experiment, a neural network based system consisting of 33 fall sequences achieved a fall detection rate of $92 \%$ and a false rate of 5\% (Belshaw et al., 2012).

Another experiment performed for fall detection, which used Support Vector Machines, had a detection rate of $97.08 \%$ and a very low rate of false detection of $0.80 \%$ on 15 scenarios (Belshaw 


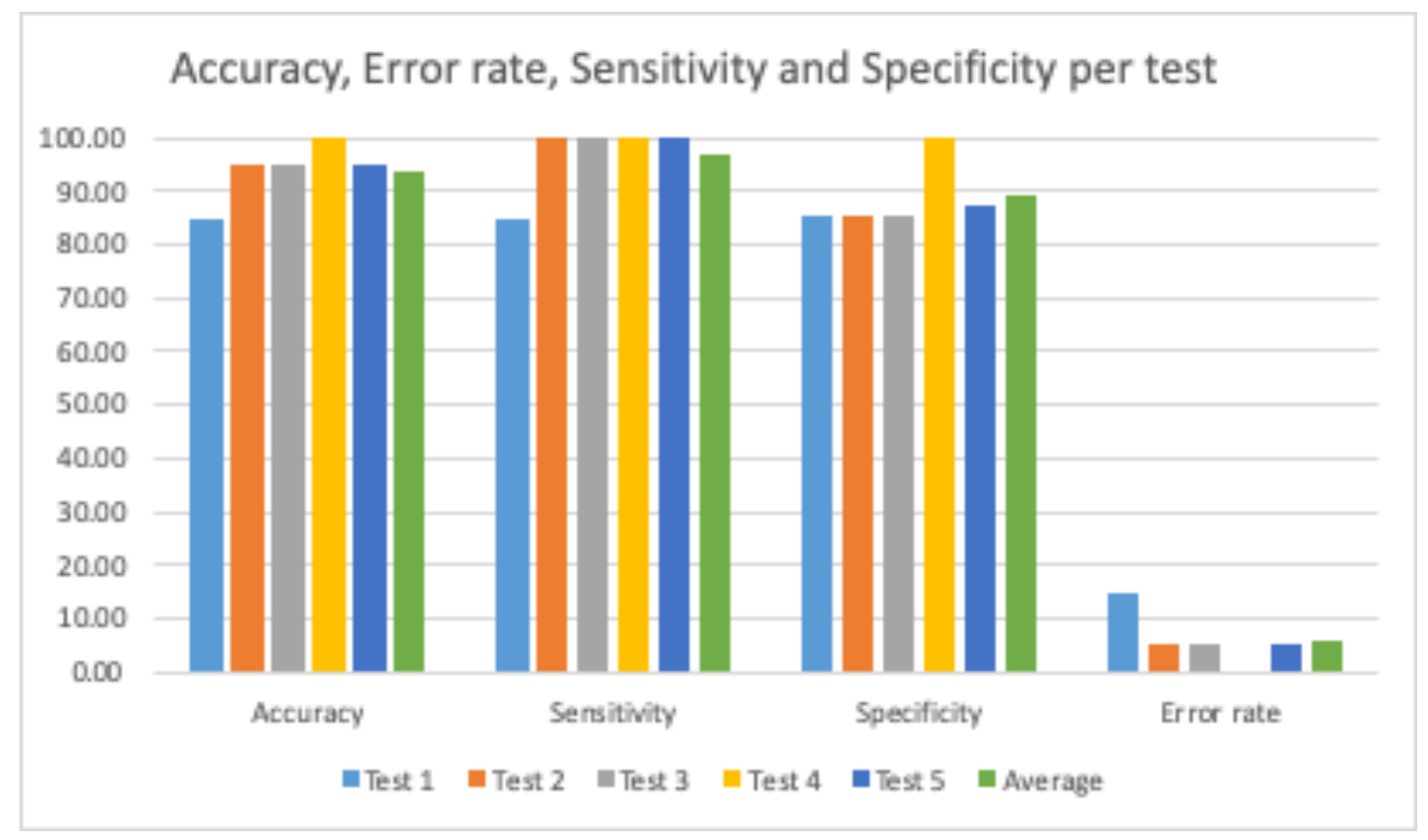

Figure 9: Results obtained from the laboratory experiment

et al., 2012). In their experimental evaluation for a computer vision-based fall detection system, Solbach and Tsotsos (2017) recorded a fall detection rate of 91\% from 20 scenarios.

The systems mentioned in the above paragraph have comparative results to the evaluation results of the SHE prototype developed in this research. They mainly focused on fall detection and the analysis of activities of daily living to detect falls. The $94 \%$ average accuracy obtained from this research is significant as it lies within the range of the accuracy of similar evaluations.

\section{CONCLUSION}

The risks facing the elderly living independently were identified from literature and a focus group interview with the elderly. The requirements of the SHE were determined to be fall detection, home environment monitoring, inactivity monitoring and emergency notification. A low cost SHE prototype was developed based on the requirements and a review of some of the existing solutions. The SHE prototype consists of a data collection layer, data processing and computation layers and the services/applications layer. When an abnormal situation is detected, a notification is sent to the registered recipient as a push notification.

The prototype was evaluated to determine the accuracy, sensitivity, specificity and consistency in detecting potential risks. An average accuracy of $94 \%$ was obtained from the results of the evaluation with an error rate of $6 \%$. The average sensitivity obtained was $96.92 \%$ and the average specificity was $88.93 \%$. In comparison to the evaluation results from similar work, the SHE prototype was able 
to accurately and consistently support safety and risk monitoring in the home in accordance with the requirements of the elderly living independently. Fall detection systems and risk monitoring systems notification systems are not $100 \%$ accurate, due to various limitations, which result in false positives (El-Bendary et al., 2013).

The results of the research show that the objectives of the research were met and that the SHE prototype was able to effectively support safety and risk monitoring for the elderly.

\section{References}

Belshaw, M., Taati, B., Jasper, S., \& Mihailidis, A. (2012). Towards a single sensor passive solution for automated fall detection. 2011 Annual International Conference Proceedings of the IEEE Engineering in Medicine and Biology Society, 1773-1776. https://doi.org/10.1109/IEMBS. 2011.6090506.Towards

El-Bendary, N., Tan, Q., Pivot, F. C., \& Lam, A. (2013). Fall detection and prevention for the elderly: A review of trends and challenges. International Journal on Smart Sensing and Intelligent Systems, 6(3), 1230-1266. Retrieved from http://www.s2is.org/Issues/v6/n3/papers/paper23.pdf

Breen, R. L. (2006). A practical guide to focus-group research. Journal of Geography in Higher Education, 30(3), 463-475. https://doi.org/10.1080/03098260600927575

Burrows, A., Gooberman-Hill, R., \& Coyle, D. (2015). Empirically derived user attributes for the design of home healthcare technologies. Personal and Ubiquitous Computing, 19(8), 1233-1245. https://doi.org/10.1007/s00779-015-0889-1

Cheek, P., Nikpour, L., \& Nowlin, H. D. (2005). Aging well with smart technology. Nursing Administration Quarterly, 29(4), 329-338. https://doi.org/00006216-200510000-00007

Chiarini, G., Ray, P., Akter, S., Masella, C., \& Ganz, A. (2013). mHealth Technologies for Chronic Diseases and Elders: A Systematic Review. IEEE Journal on Selected Areas in Communications, 31(9), 6-18. https://doi.org/10.1109/JSAC.2013.SUP.0513001

Chiridza, T., Wesson, J., \& Vogts, D. (2016). A smart home environment to support health care for the elderly. In Proceedings of the 2016 Southern Africa Telecoms and Network Applications Conference.

Christensen, L. R., \& Grönvall, E. (2011). Challenges and opportunities for collaborative technologies for home care work. Proceedings of the 12th European Conference on Computer Supported Cooperative Work, 24-28 September 2011, (September), 24-28. https://doi.org/10.1007/9780-85729-913-0_4

Cook, D. J., \& Krishnan, N. (2014). Mining the home environment. The Medical Journal of Australia, 2(2), 54-55. https://doi.org/10.1007/s10844-014-0341-4.Mining

Costa, Å., Castillo, J. C., Novais, P., Fernández-Caballero, A., \& Simoes, R. (2012). Sensor-driven agenda for intelligent home care of the elderly. Expert Systems with Applications: An International Journal, 39(15), 12192-12204.

Deen, M. (2015). Information and communications technologies for elderly ubiquitous healthcare in a smart home. Personal and Ubiquitous Computing, 19(3-4), 573-599. https://doi.org/10. 1007/s00779-015-0856-x 
Delahoz, Y. S., \& Labrador, M. A. (2014). Survey on fall detection and fall prevention using wearable and external sensors. Sensors (Switzerland), 14(10), 19806-19842. https://doi.org/10.3390/ s141019806

Demiris, G., Hensel, B. K., Skubic, M., \& Rantz, M. (2008). Senior residents' perceived need of and preferences for "smart home" sensor technologies. International Journal of Technology Assessment in Health Care, 24(1), 120-4. https://doi.org/10.1017/S0266462307080154

Doody, O., Slevin, E., \& Taggart, L. (2013). Focus group interviews part 3: Analysis. British Journal of Nursing, 22, 266-9. Retrieved from http://www.ncbi.nlm.nih.gov/pubmed/23545552

Gómez-Olivé, F. X., Thorogood, M., Clark, B., Kahn, K., \& Tollman, S. (2013). Self-reported health and health care use in an ageing population in the Agincourt sub-district of rural South Africa. Global Health Action, 6, 19305. https://doi.org/10.3402/gha.v6i0.19305

Hevner, A. R., \& Florida, S. (2011). Design Science in Information Systems Research. Last checked: 14 Jul 2019. Retrieved from http://misrc.umn.edu/seminars/slides/2006/12152006_ Seminar_BW.pdf

Hjalmarsson, A., \& Rudmark, D. (2012). Design science research in Information Systems: Advances in theory and practice. In Lecture Notes in Computer Science 7286 (pp. 9-27). Springer.

Home Accident Prevention for Elderly. (2002). Retrieved May 16, 2016, from http://www.hkfsd. gov.hk/eng/source/safety/Elderly\%7B\%5C_\%7Dhome\%7B\%5C_\%7Daccident.html

Koshmak, G., Loutfi, A., \& Lindén, M. (2015). Challenges and issues in multi-sensor fusion approach for fall detection: Review paper. Journal of Sensors, 2016, 1-13.

Lê, Q., Nguyen, H. B., \& Barnett, T. (2012). Smart homes for older people: Positive aging in a digital world. Future Internet, 4(2), 607-617. https://doi.org/10.3390/fi4020607

Lim, D., Park, C., Kim, N. H., Kim, S. H., \& Yu, Y. S. (2014). Fall-detection algorithm using 3-axis acceleration: Combination with simple threshold and hidden Markov model. Journal of Applied Mathematics, 2014. https://doi.org/10.1155/2014/896030

Liu, H., \& Zuo, C. (2012). An improved algorithm of automatic fall detection. AASRI Procedia, 1, 353-358. https://doi.org/10.1016/j.aasri.2012.06.054

Mckinley, T. (2014). User-centered design in smart home technology for the elderly. Electronic Journal of Health Informatics, 1-5.

Moeller, S., Krebber, J., Raake, A., Smeele, P., Rajman, M., Melichar, M., ... Potamitis, I. (2004). INSPIRE: Evaluation of a smart-home system for infotainment management and device control. Arxiv preprint cs0410063, 4. arXiv: 0410063 [cs]. Retrieved from http://arxiv.org/abs/cs/ 0410063

Mubashir, M., Shao, L., \& Seed, L. (2013). A survey on fall detection: Principles and approaches. Neurocomputing, 100, 144-152. https://doi.org/10.1016/j.neucom.2011.09.037

OpenHAB. (2016). openHAB. Retrieved December 16, 2016, from http://www.openhab.org/

Powell, R. A., \& Single, M. (1996). Methodology matters V: Focus groups. International Journal for Quality of health care, 8(5), 499-504. https://doi.org/10.1093/intqhc/8.5.499

Prat, N., Comyn-Wattiau, I., \& Akoka, J. (2014). Artifact evaluation in information systems design science research-A holistic view. In PACIS 2014 Proceedings (Vol. Paper 23, pp. 1-16). Retrieved from http://aisel.aisnet.org/pacis2014/23/ 
Pries-Heje, J., Baskerville, R. L., \& Venable, J. R. (2008). Strategies for Design Science Research Evaluation. European Conference on Information Systems (ECIS), Paper 87, 1-13. https://doi. org/10.1177/1933719108329095

Rashidi, P., Cook, D. J., Holder, L. B., \& Schmitter-Edgecombe, M. (2011). Discovering activities to recognize and track in a smart environment. IEEE Transactions on Knowledge and Data Engineering, 23(4), 527-539. https://doi.org/10.1109/TKDE.2010.148

Röcker, C. (2013). Intelligent environments as a promising solution for addressing current demographic changes. International Journal of Innovation, Management and Technology, 4(1), 76-79. https://doi.org/10.7763/IJIMT.2013.V4.361

Saito, T., \& Rehmsmeier, M. (2017). Basic evaluation measures from the confusion matrix - Classifier evaluation with imbalanced datasets. Retrieved February 20, 2017, from https://classeval. wordpress.com/introduction/basic-evaluation-measures/

Solbach, M. D., \& Tsotsos, J. K. (2017). Vision-based fallen person detection for the elderly. arXiv: 1707.07608. Retrieved from http://arxiv.org/abs/1707.07608

Thomas, K., Becker, M., Ras, E., Holzinger, A., \& Müller, P. (2007). Ambient intelligence in assisted living: Enable elderly people to handle future interfaces. Universal Access in Human-Computer Interaction. Ambient Interaction, 103-112. https://doi.org/10.1007/978-3-540-732815_11

Todd, C., \& Skelton, D. (2004). What are the main risk factors for falls amongst older people and what are the most effective interventions to prevent these falls? World Health, (March), 28.

vergaard Hansen, F. O. (2014). Ambient assisted living healthcare frameworks, platforms, standards, and quality attributes. https://doi.org/10.3390/s140304312. arXiv: arXiv:1408.1149

Villalba, E., Arredondo, M. T., Ottaviano, M., Salvi, D., Hoyo-Barbolla, E., \& Guillen, S. (2007). Heart failure monitoring system based on wearable and information technologies. Journal of Communications, 2(2), 10-21. https://doi.org/10.4304/jcm.2.2.10-21

Wold, G. H. (2012). Meeting safety needs of older adults. In Basic Geriatric Nursing (Vol. 6th, pp. 167179).

Zivkovic, Z., \& Van Der Heijden, F. (2006). Efficient adaptive density estimation per image pixel for the task of background subtraction. Pattern Recognition Letters, 27(7), 773-780. https: //doi.org/10.1016/j.patrec.2005.11.005 